REVISTA DE LA CEPAL 84 . DICIEMBRE 2004

\title{
La renovada
}

\section{contemporaneidad de Raúl Prebisch}

\author{
Rubens Ricupero
}

1

artículo comienza con una breve evocación de los rasgos principales de la herencia de Raúl Prebisch, no solo desde el punto de vista estrictamente intelectual, sino también como modelo de humanista. En seguida trata de la coyuntura por la que atraviesa el mundo actual, haciendo hincapié en el comercio; destaca el retorno del espíritu de economía de guerra y la inestabilidad en el mercado del petróleo, factores que conspiran contra la mayor inversión necesaria para que la economía mundial crezca satisfactoriamente, y señala que, pese a ello, en la coyuntura actual hay una recuperación del crecimiento y una revitalización del comercio. Por último, analiza los cambios estructurales en el sistema comercial que ya han ocurrido o están en curso y, en particular, en qué medida esos cambios se parecen a los que Prebisch esperaba, o se han alejado de esas expectativas. 


\title{
I
}

\section{Introducción}

En este artículo, deseo ante todo evocar los que son, en mi opinión, los rasgos principales de la herencia de Raúl Prebisch, no tanto desde el punto de vista estrictamente intelectual sino como modelo de humanismo. En segundo lugar, quiero referirme a lo que podríamos llamar el aquí y el ahora, la coyuntura, lo que ocurre en el mundo actual, con énfasis en el comercio, mi área principal de experiencia. Por circunstancias de la vida diplomática, el vínculo que he tenido con el comercio ha sido quizás mi rasgo distintivo por excelencia, el que me ha diferenciado de mis cuatro antecesores en la UNCTAD. Ellos no tuvieron una experiencia directa en el Acuerdo General de Aranceles Aduaneros y Comercio (GATT), como la tuve yo en los puestos de dirección y de negociador que ocupé, experiencia que quizás me ha ayudado a desarrollar una visión diferente que solo puede nacer de la realidad negociadora de los acuerdos de comercio.

En tercer lugar, pasaré revista a los cambios estructurales en el sistema comercial que ya han ocurrido o que están en marcha, y examinaré particularmente en qué medida esos cambios se parecen a los que Prebisch deseaba, o se han alejado de sus expectativas. Por último, expresaré una breve conclusión sobre la situación de América Latina, que es mi tierra y donde espero vivir dentro de muy poco tiempo y seguir colaborando con la CEPAL desde una posición más cercana.

\section{II}

\section{La herencia intelectual y humanista de Prebisch}

\author{
“... si miráramos hoy los momentos que estamos atravesando no \\ podríamos ser optimistas. Yo creo que hay que seguir en la lucha, \\ que no solamente concierne al ámbito internacional sino a nuestros \\ propios países. No se trata solamente de un nuevo orden económico \\ internacional, sino de un nuevo orden económico social y ético interno. \\ Esos son los grandes problemas que tenemos que resolver en la \\ América Latina, tras duros sacrificios" (Prebisch,1983).
}

Estas palabras de Raúl Prebisch cerraron la primera de la serie de conferencias instituidas por la UNCTAD en su honor y fueron pronunciadas en Ginebra el 6 de julio de 1982. Ellas ponen de manifiesto lo que, a mi juicio, es lo más importante de todo cuanto él nos ha dejado: su compromiso ético y moral con la promoción social de los latinoamericanos.

Este artículo recoge una conferencia magistral dictada por el autor en la Comisión Económica para América Latina y el Caribe (Santiago de Chile, 27 de agosto de 2004), en el marco de la Cuarta Cátedra Raúl Prebisch.
Yo utilicé otra frase de la misma conferencia para inaugurar mi intervención en las conmemoraciones del centenario del nacimiento de Prebisch, organizadas por la CEPAL en Santiago de Chile. Esa intervención la denominé "La globalización de Raúl Prebisch", explicando que daba al término globalización un doble significado. "Primero, dicho término explica el sentido del itinerario personal de Prebisch hacia una creciente universalización: desde la Argentina natal hacia América Latina y desde ésta al conjunto del sistema de la economía mundial en la UNCTAD. Segundo, sugiere que una de las mejores maneras de recordar a este gran latinoamericano es intentar imaginar cómo sería la globalización si ella fuera diseñada por él, en vez de 
aquella globalización real con las características que generan y provocan un movimiento popular de contestación..." (Ricupero, 2001).

Deseo referirme aquí, no a la evolución que llevó al pensamiento de Prebisch a abarcar un espacio cada vez más amplio, hasta confundirse con la totalidad del sistema económico planetario, sino a la permanencia de ese pensamiento en el tiempo, a su constante actualización, a lo que se podría llamar su renovada contemporaneidad. No quiere eso decir que él no se haya equivocado, que sus ideas fuesen intemporales, ni que se deba olvidar lo que él mismo dijo en su contribución a Pioneros del desarrollo: que su "pensamiento sobre el desarrollo ha atravesado por etapas sucesivas bajo la influencia de una realidad cambiante y del ensanchamiento de mi experiencia propia" (Prebisch, 1984).

Lejos de dejarse inmovilizar por ideologías o ideas inmutables, "lo que es notable", comenta Jagdish N. Bhagwati, es "cómo él ha sido capaz de interaccionar con su ambiente económico y político y, de esa forma, elevar su estatura de economista" (Bhagwati, 1984).

La actualidad de un pensamiento no se mide por el balance contable de aciertos y errores, sino por la relevancia perenne de sus temas y preocupaciones, tal vez de sus preguntas aún más que de sus respuestas. Así, todos los temas principales de la obra futura de Prebisch y del debate de hoy están ya presentes en $E l$ desarrollo económico de la América Latina y algunos de sus principales problemas (Prebisch, 1949): el dualismo centro-periferia; su "espléndida terminología", como dice Bhagwati; la importancia central del progreso técnico, el nexo entre comercio exterior y desarrollo, la inversión extranjera, la sustitución de importaciones, la interdependencia, los precios de las materias primas.

Otro elemento básico de la influencia del ejemplo de Prebisch aparece también en ese lejano estudio: el énfasis que él pone en partir de la propia realidad para crear una reflexión adaptada a las circunstancias de espacio y tiempo. Como él escribe entonces: "No hay que confundir el conocimiento reflexivo de lo ajeno con una sujeción mental a las ideas ajenas, de la que muy lentamente estamos aprendiendo a liberarnos" (Prebisch, 1949). Treinta y tres años más tarde, en la conferencia Prebisch de la UNCTAD de 1982, él retornaría a ese enfoque: "En aquellos años de la gran depresión comenzó en la América Latina un fenómeno de emancipación intelectual que consistía en contemplar con sentido crítico las teorías de los centros. Y ello sin una actitud de arrogancia intelectual —esas teorías tienen gran valor - sino dándose cuenta que habría que estudiarlas con sentido crítico. (...) es ese examen crítico que nos llevó a esforzarnos por buscar nuestras propias vías del desarrollo — - vías no imitativas- a tratar de comprender esta realidad y responder a las exigencias económicas, sociales y morales del desarrollo —vías de la equidad" (Prebisch, 1983).

La actitud de tratar consistentemente de juzgar las teorías a la luz de sus resultados prácticos, de hacer esa prueba de viabilidad, nunca lo abandonará. Sus referencias a lo que está pasando en el mundo, en los centros, en los Estados Unidos y, con más frecuencia, en América Latina, hacen de él un pensador siempre dispuesto y abierto al cambio, a lo nuevo, a la autocrítica. Contemporáneo de Ortega y Gasset, encarnó como pocos la circunstancia latinoamericana, su circunstancia personal y nacional.

En ese sentido, es curioso cómo en el ensayo sobre sus "cinco etapas" (Prebisch, 1984) él no se adentra en su experiencia de "globalización" personal -que corresponde al cuarto estadio, el de la UNCTAD-, lo que no escapa a dos comentaristas del texto, Albert Fishlow y Jagdish N. Bhagwati. No debe verse en ello la manifestación de una frustración o sensación de fracaso más acentuada con respecto a esa etapa de su itinerario intelectual, pues sus textos finales sobre la América Latina de las dictaduras militares y de la crisis de la deuda en la "década perdida" de 1980, no están más henchidos de esperanza. La explicación sencilla, creo, es que él tenía que retornar cada vez a la circunstancia latinoamericana a fin de alimentar su comprensión del mundo a partir de una realidad que es la suya. Su raigambre latinoamericana es tan fuerte que se convierte en un hábito, quizás, inconsciente. Hasta el punto de que en un texto destinado en principio a un auditorio internacional $y$, en lo que atañe a los países en desarrollo, al conjunto de la periferia como un todo, él termina sus palabras pasando de lo general —el ámbito internacional — a lo particular: "Esos son los grandes problemas que tenemos que resolver en la América Latina tras duros sacrificios" (Prebisch, 1983), como si los problemas no fueran los mismos en otros continentes.

En el mismo texto, él lamentaba que "cuando vinieron esos grandes años de prosperidad y nos dejamos deslumbrar por los centros, ese esfuerzo de búsqueda de nuestros propios caminos quedó interrumpido" (Prebisch,1983). En una sorprendente anticipación de algunas tendencias actuales, él criticaba que "las iniciativas de comercio recíproco entre los países de la región se debilitaron considerablemente, porque 
creíamos que ya se abría una nueva era para el mundo, en la cual las exportaciones de manufacturas a los centros iban a resolver los grandes problemas de estrangulamiento exterior... Nos dejamos seducir, lo que es natural, por las consecuencias de la prosperidad de los centros. El péndulo fue al otro lado, nada de sustitución, nada de esfuerzos de comercio recíproco, todo nuestro porvenir estaba en el crecimiento hacia afuera, en la explotación de los mercados de los centros" (Prebisch, 1983).

Palabras como esas describen incluso mejor lo que ocurre hoy en día que lo que sucedía en 1982, que marcaría, meses después de la reunión de la UNCTAD, en julio de ese año, el comienzo de la larga crisis de la deuda externa de la región, con el colapso mexicano de octubre y la década o década y media perdidas. No sería difícil encontrar otros ejemplos de la extraordinaria lucidez de la visión casi profética de Prebisch, la capacidad de prever numerosos fenómenos que son ahora más claramente decisivos que en la época en que él los describió.

Ahora bien, en lugar de hacer un balance exhaustivo, destacaré dos aspectos fundamentales y permanentes del legado intelectual de Prebisch. El primero es lo que se puede llamar su actitud frente al mundo: la búsqueda de un camino latinoamericano propio, basado en nuestra realidad, como uno de los criterios principales para evaluar y adaptar críticamente las teorías y terapias importadas.

El segundo es lo que está en la raíz de la crítica que emprende en contra de los excesos del cambio radical de orientación de los gobiernos de la región en la década de 1980, y que él resume de la siguiente manera: “... mirando hacia afuera, hemos abandonado lo que, a mi juicio, era una política que con todos sus defectos y fallas considerables - que las tuvo- debiera haberse seguido, aprovechando la experiencia adquirida para irla depurando" (Prebisch, 1983). La razón de su rechazo a lo que llama "teorías convencionales" es que ellas hacían caso omiso de la estructura social y sus continuas mutaciones. Además de las insuficiencias que identifica en la capacidad de explicación de las teorías convencionales, incluso en lo que respecta al sistema económico de los centros, lo que le parece más grave es que, aplicadas a América Latina, esas fórmulas obligarían a dejar "al margen la gran masa de la población a la cual no había llegado sino en forma incipiente la industrialización" (Prebisch, 1983).

El mecanismo de la marginalización comienza con la imitación frenética de las formas avanzadas de consumo de los centros por los grupos sociales supe- riores de la periferia latinoamericana. Gracias a las grandes disparidades en la distribución del ingreso esos grupos tuvieron la posibilidad de asimilar rápidamente las formas de consumo de los centros. Eso ocurre "en detrimento de la acumulación de capital reproductivo, que es lo único que puede resolver nuestros problemas de exclusión social, es decir, el hecho de que grandes masas de la población quedan rezagadas en el fondo del sistema, con bajos ingresos, con muy baja productividad y muchos de sus miembros desocupados, porque no se ha acumulado suficiente capital reproductivo que haga crecer el empleo y la productividad de las masas" (Prebisch, 1983).

Esa descripción de la realidad latinoamericana fue esbozada hace exactamente 22 años, el espacio de una generación histórica. A todos nos gustaría poder decir que ella no es más que eso, algo pasado, superado, que pertenece en definitiva a una historia en vías de ser olvidada. ¿Será posible sustentar tal posición cuando leemos el Balance preliminar de las economías de América Latina y el Caribe 2003 (CEPAL, 2003) publicado en diciembre del año pasado? Ese balance contiene la siguiente frase, lamentando que, no obstante su crecimiento de 2003, el PIB per cápita de la región se haya mantenido estancado, un $1,5 \%$ por debajo del nivel de 1997: "Los seis años de crecimiento negativo por habitante provocaron daños sociales que tardarán en revertirse. En 2003 hay 20 millones más de latinoamericanos pobres que en 1997. La tasa de desempleo ha crecido dos puntos en este período, ascendiendo a 10,7\%" (CEPAL, 2003). En otro sitio, la publicación citada nos informa que la pobreza afectaba, en aquel momento, al $44 \%$ de la población.

Estoy consciente, como es obvio, de que esas cifras preocupantes son el resultado de una coyuntura particularmente adversa que refleja, entre otros factores, el colapso financiero argentino de 2001 y las consecuencias económico-sociales de los problemas políticos en Venezuela y otros países. No ignoro que se trata de un promedio y que hay excepciones esperanzadoras de países que han logrado reducir significativamente la pobreza y que crecen gracias a sólidas políticas macroeconómicas, como es, entre otros, el caso de Chile, que todos admiramos. Tampoco desconozco que las perspectivas más halagadoras de crecimiento de 2004, y ojalá de los próximos años, deben en breve producir resultados positivos en la reducción del desempleo.

Sin embargo, hay una realidad que no se puede ignorar y que permite argumentar que la visión de Prebisch conserva su carácter contemporáneo. 
Armados con esas herencias definidoras, el compromiso moral con un desarrollo socialmente equitativo y una actitud intelectual crítica y sin prejuicios ideológicos construida a partir de nuestra realidad, cerra- mos esta sección y pasamos a la siguiente, inspirándonos en otra exhortación de Prebisch, título de su conferencia en Medellín en 1986 poco antes de morir: "Renovar nuestras ideas, un imperativo".

\section{III}

\section{El aquí y el ahora}

El 27 de agosto de 2004 se completaron tres años desde las conmemoraciones del centenario de Prebisch en la CEPAL. Allí hablé el 28 de agosto de 2001, precisamente 15 días antes de los atentados terroristas que cambiaron el mundo el 11 de septiembre de aquel año.

En ese entonces no teníamos idea de lo que iba a pasar en el mundo ni de los cambios que iban a ocurrir a partir de ese momento. No intentaré hacer un balance exhaustivo de esos cambios. Solamente me referiré a algunos de ellos, en la medida en que tienen influencia sobre el ambiente económico y comercial, principal tema de este artículo.

Me gustaría señalar primero que lo que realmente ha cambiado es que hemos pasado a vivir nuevamente en una economía de guerra. En ciertos aspectos, a veces podría parecernos que hemos vuelto al decenio de 1970, cuando la economía de guerra debida al conflicto en Vietnam se había combinado con otros factores que hoy día no están presentes, como por ejemplo, la inflación.

Tenemos en la actualidad por lo menos dos aspectos que se asemejan a los de esa época: una economía de guerra nuevamente asociada a una gran inestabilidad en los mercados del petróleo. Cuando me refiero a una economía de guerra, lo que quiero decir es que hemos dejado atrás una atmósfera mental en que nos dominaba la idea de que lo que importaba era la globalización económica. Entre la caída del muro de Berlín y los atentados terroristas, lo que se consideraba importante era el mercado, la globalización, la facilitación de las transacciones de todo género. Hemos pasado de esa actitud mental a otra en la que predominan las preocupaciones por la seguridad. Los estadounidenses afirman que están en una guerra contra el terrorismo que no sabemos cuando terminará. En menos de tres años ya tuvimos una guerra en Afganistán, otra en Irak, y ya se puede leer en los diarios que hay planes, no para ir a la guerra, sino para desestabilizar países como Irán. Son planes serios anunciados en cierta medida en diarios destacados como el Times de Londres.

Es este un período casi de movilización permanente, en que un conflicto no lleva a la paz sino a un nuevo conflicto, con la utilización cada vez mayor de recursos humanos, militares y financieros. ¿Cómo va a terminar? No tengo idea ni quiero hacer predicción alguna. Constato solamente el hecho de que hay una economía de guerra, cuya primera consecuencia es el fortalecimiento desmesurado del Estado, del poder del Estado. El Estado se fortalece frente al mercado y frente a la sociedad civil, y se fortalece porque las consideraciones militares, estratégicas, de seguridad y políticas pasan a ser cuestiones de vida o muerte. Como dijo Napoleón, "la intendencia sigue"; la economía, el comercio, las finanzas, todo eso tiene que seguir.

El Estado destina recursos a fortalecer su seguridad. No es por otra razón que en la campaña electoral estadounidense las preocupaciones por el déficit fiscal son menos importantes que las preocupaciones estratégicas. No es por otra razón que se votan aumentos extraordinarios de créditos para crear nuevas capacidades, ya sea para la seguridad en el exterior o para la interior. Se trata, por lo tanto, de una transformación profunda. No sé cuánto va a durar, pero a mi juicio, es incompatible a largo plazo con lo que era la idea de la globalización.

¿Cuál era la idea fuerza de la globalización? Era la creencia en que las fronteras seguirían ahí pero se volverían irrelevantes porque las transacciones, cada vez más fáciles, no se harían de un lado a otro de las fronteras (crossborder), sino que se harían por encima de ellas (transborder), como las transacciones electrónicas transportadas por internet que no son captadas por ningún tipo de aduana. Esa era la convicción que subyacía la globalización: que las mercancías pueden traspasar las fronteras y que lo mismo harían los empresarios (no los trabajadores, eso no se ha agregado nunca), los préstamos y las inversiones. 
Si dura demasiado la preocupación excesiva por la seguridad, no es que se vaya a terminar con la globalización, pero los obstáculos se multiplicarán. Quienes hayan visitado los Estados Unidos recientemente saben de lo que estoy hablando. No es preciso dar muchos ejemplos. Ha habido un cambio radical, importante. Es la vuelta del espíritu de una economía de guerra. Lo ocurrido con una zona de alto valor estratégico en la producción del petróleo obviamente impacta sobre los precios de este producto. Entre las numerosas razones que se han dado para explicar la guerra de Irak, confesadas y no confesadas - la existencia de armas de destrucción masiva, los posibles vínculos con el movimiento terrorista-, estaba la idea de que un Irak pacificado, democrático, sería una garantía más de suministro regular de petróleo. También este motivo ha resultado ser falso, porque ahora las frecuentes interrupciones de la producción en Irak son uno de los factores que causan la volatilidad de los precios. Al factor Irak se suman otros, como el aumento de la demanda de países como China, los problemas en Rusia vinculados con la empresa Yucos, las dificultades políticas en Venezuela, y, sobre todo, la pesadilla más grave, la creciente inestabilidad de Arabia Saudita.

Por sí sola, Arabia Saudita genera más de $10 \%$ del suministro de petróleo. En 1979, cuando la revolución de los ayatolas retiró por algún tiempo del mercado el petróleo iraní - que en volumen no se compara con el de Arabia Saudita - hubo un aumento del precio del barril que hoy, corregido, sería equivalente a 100 dólares. ¿Qué ocurriría si algo similar pasara con Arabia Saudita? Estoy singularizando esos dos factores, la economía de guerra y el petróleo, por una razón muy sencilla: es que ambos afectan el sentimiento de seguridad de quienes deciden sobre las inversiones.

La economía mundial sólo crecerá a tasas satisfactorias si la inversión es cada vez más alta. Pero está claro que en una coyuntura como la actual, en que la preocupación principal es la inseguridad, lo imprevisible de una economía de guerra y de los precios del petróleo, no cabría esperar nuevamente un movimiento importante de inversión. Creo que este es un factor coyuntural importantísimo, aunque hay muchos otros a los que no me referiré aquí. A pesar de esta situación, hemos tenido la suerte que, después de la breve recesión en 2001, que siguió, entre otras cosas, al gran aumento del precio del petróleo en 2000, la economía mundial comenzó a recuperarse hasta el punto de que este año ya hay estimaciones de crecimiento en torno a $4 \%$. Esto se debe en gran medida al crecimiento de China y de India y a la recuperación de la economía de los Estados Unidos, aunque hoy esta comienza a despertar dudas por los resultados menos halagadores del segundo trimestre de 2004 y por el agravamiento enorme, de más de 9 mil millones de dólares, del déficit comercial de ese país en el mes de junio.

Este ambiente de crecimiento ha traído consigo una revitalización del comercio mundial, que había tenido un año excepcional en 2000 , con un crecimiento de más de $13 \%$, seguido en 2001 por una contracción de $-1 \%$, un comienzo de recuperación en 2002 y un crecimiento de 4,5\% en 2003. El excelente Balance preliminar de las economías latinoamericanas y del Caribe 2003, publicado por la CEPAL en diciembre de ese año, mostró cómo ese crecimiento ha permitido a América Latina exhibir varios récords de crecimiento de las exportaciones, un excedente comercial de 41.000 millones de dólares y un excedente en cuenta corriente de 6.000 millones de dólares. La publicación citada habla de un buen desempeño casi general, con excepción de algunos casos importantes. Ya se han visto los primeros frutos de esa recuperación del comercio, y la tendencia se ha acentuado en el año en curso. Las estimaciones más conservadoras — como las de la Organización Mundial del Comercio (OMC) - indican que el comercio puede crecer 7\% en 2004. Los datos más recientes de la Organización de Cooperación y Desarrollo Económicos (OCDE) calculan el crecimiento para este año en $8,6 \%$ y quizás en 10,2\% para el próximo, siempre y cuando los factores asociados al crecimiento mundial, como el petróleo y otros, no creen demasiados problemas.

Es verdad que, por lo menos en muchos continentes y regiones, ese crecimiento se explica en gran medida por modificaciones de los tipos de cambio y de precios de bienes y servicios. No es el caso de América Latina y aún menos el de Asia, pero en Europa occidental una buena parte del crecimiento se debe más bien a factores relacionados con los tipos de cambio y los precios. Hay que reconocer que 2004 es un año excepcional en materia de comercio, con buenas perspectivas, como las anunciadas por la OCDE para el año próximo.

Sin embargo, nos encontramos con una paradoja: ¿cómo explicar que en un año en que las cosas caminan tan bien, sólo las negociaciones comerciales anden mal? Normalmente, cuando la economía mundial crece, cuando el comercio crece, cuando hay recuperación en los precios de la mayoría de las materias primas, lo natural es la tendencia a que las negociaciones avancen. Sin embargo, hemos venido observando recientemente que, por el contrario, hubo proble- 
mas en las negociaciones de Cancún el año pasado y en las negociaciones en Ginebra en el año en curso, que no progresaron hasta el último momento, creando el temor de que no se llegaría a un acuerdo. Las negociaciones sobre el Área de Libre Comercio de las Américas (ALCA) prácticamente dejaron de existir, por lo menos como fueron planteadas en su origen. Actualmente el ALCA ya no es lo mismo que se había propuesto en sus comienzos hace 10 años. Las negociaciones entre el Mercosur y la Unión Europea tampoco han realizado grandes avances. Hubo algunos acuerdos de libre comercio - entre ellos, el de Chile con los Estados Unidos- pero ninguno que pueda llamarse un hito en temas álgidos. Por ejemplo, el acuerdo entre Australia y Estados Unidos prácticamente no ha tenido ningún impacto positivo inmediato en temas espinosos como los relativos a la agricultura.

¿Cómo explicar esta aparente contradicción? La explicación, a mi juicio, es muy sencilla: el problema es más político que económico o comercial. De hecho, las negociaciones comerciales que en el GATT se concentraron por largos años en los aranceles industriales, prácticamente se han agotado, puesto que los temas fáciles ya se trataron. Lo que queda ahora es lo difícil. La esencia de los temas proteccionistas, lo que se llamó en Ginebra la tarea inconclusa de la Ronda de Tokio y la Ronda Uruguay (es decir, el trabajo sin terminar de todas las rondas), lo que son los problemas difíciles, quedaron por resolver.

El GATT pudo avanzar muy rápidamente en los decenios de 1950, 1960 y 1970 porque se dejaron de lado los temas más arduos: la agricultura, los textiles, las prendas de vestir, el calzado, los artículos de cuero. Todos esos productos quedaron aislados, sujetos a reglas especiales.

Se ha avanzado en los sectores en que todos han querido avanzar, pero tarde o temprano habrá que enfrentarse con el problema fundamental. No fue sin razón que esos temas se dejaron de lado, pues son sumamente complejos. Y ahora, cuando ha llegado finalmente el día de encararlos, se está comprobando que realmente el reto es muy grande. No es algo que va a desaparecer con las elecciones estadounidenses. En lo que atañe a la agricultura, por ejemplo, estoy seguro de que las dificultades serán muy grandes y durarán muchos años. Esto va a ser el resultado no sólo de la renuencia de Europa y los Estados Unidos, sino también de la de grandes países en desarrollo como China, India y otros.

Este problema de la coyuntura ha tenido hace pocas semanas un resultado halagador: con un acuer- do marco para permitir solamente que las negociaciones no terminen. En realidad, si uno quiere definir el contenido real de ese acuerdo, hay que reconocer que es extremadamente minimalista. La ventaja del acuerdo es que se ha evitado lo peor, es decir, se ha evitado que la Ronda de Doha muera. Dicha ronda debía terminar a fines de 2004. Si no se hubiese logrado ni siquiera el compromiso de seguir negociando, hubiera perecido de inanición, por falta de alicientes. El acuerdo que se ha logrado, construido sobre numerosas ambigüedades creativas, hace posible que las negociaciones se reanuden el próximo año. En el sector agrícola, en los llamados tres pilares de la agricultura, hay ese tipo de ambigüedad. Sobre los subsidios a la exportación se acepta la idea de que, en algún momento, en alguna fecha, en un futuro incierto y no conocido, habrá que terminar con ellos. ¿Cuál será la fecha? No se sabe, y el objetivo sólo podrá lograrse si hay progresos paralelos en otras formas de subsidios, créditos, ayuda en alimentos, etc.

En cuanto a medidas internas de apoyo a la agricultura, si bien es cierto que se llegó a un acuerdo en principio sobre límites que no se deben sobrepasar, no es menos cierto que se ha permitido igualmente, por lo menos en principio, examinar con cierta flexibilidad la llamada "caja azul", ${ }_{1}$ y con ella, la posibilidad de permitir que países como Estados Unidos legalicen a través de las negociaciones lo que han perdido en el sistema de solución de conflictos. No es que el acuerdo estipule que eso va a ocurrir, pero sí deja abierta la posibilidad.

En lo que respecta al acceso a mercados de productos agrícolas, todo está por hacerse. En materia de productos industriales el acuerdo es bastante vago, y no establece normas para definir si la negociación en ciertos sectores en que se llevaría el arancel a cero debía ser obligatoria o voluntaria. Quedan aún por resolver unas cinco, seis o siete cuestiones clave en las negociaciones, sin que se pueda predecir cuál será el resultado.

A pesar de todo lo antedicho, el acuerdo sin duda es positivo y representa lo máximo que podía lograrse en ese momento. Permite mantener vivo el sistema multilateral, pues gracias a él las negociaciones pueden comenzar de nuevo con más vigor, una vez pasada una

\footnotetext{
${ }^{1} \mathrm{La}$ "caja azul" se refiere a medidas de ayuda interna limitantes de la producción, específicamente exentas de compromisos de reducción, según acuerdo bilateral entre Estados Unidos y la Unión Europea.
} 
coyuntura política desfavorable. Creo que hay una posibilidad razonable de que esas negociaciones terminen, no en 2005, sino, al menos en los aspectos fundamentales, a fines de 2006. El mandato negociador que otorga al poder ejecutivo la Autoridad de Promoción Comercial estadounidense expira el $1^{\circ}$ de junio de 2005 , pero contiene una cláusula de prórroga casi automática por dos años, es decir, hasta junio de 2007. A mi juicio, lo más probable es que las negociaciones tengan éxito y que haya avances progresivos. En otras palabras, yo apostaría a que los resultados serán moderadamente positivos, dentro de un horizonte no lejano.

\section{III}

\section{Cambios estructurales en el sistema internacional de comercio}

Paso ahora a analizar los que en mi opinión son los grandes cambios estructurales, no en lo que atañe a temas políticos ni de seguridad, sino específicamente al sistema de comercio. No abordaré todo lo que propuso Prebisch, sino que me concentraré en algunos aspectos fundamentales de su pensamiento, para ver después cómo y en qué medida ellos han evolucionado en la práctica.

Me referiré en primer lugar al sistema mundial de comercio: ¿qué esperaba Prebisch de la institucionalización de ese sistema? En segundo lugar, a la exportación de manufacturas y, en tercer lugar, a la reciprocidad real, no legal o aparente, frente a los países en desarrollo, y al "trato especial y diferenciado" frente al Sistema Generalizado de Preferencias. Trataré además el asunto de los servicios, si bien estos no fueron parte de las preocupaciones de Prebisch. Por último, formularé algunas consideraciones sobre un tema que él anticipó muy bien, el de la interdependencia.

Quiero dejar claro que lo que haré aquí es plantear los problemas, porque no tengo realmente muchas propuestas para resolver las dificultades. Ese es el desafío que vamos a encarar en el futuro. El primer problema es el del sistema internacional o multilateral de comercio. Tomo como punto de partida el gran informe que Raúl Prebisch presentó a la primera UNCTAD, en 1964, hace 40 años. En ese informe Prebisch decía que el GATT estaba lejos de la universalidad que requería para ser realmente eficaz e internacional. Los miembros del GATT eran en ese entonces algo más de 60. Por añadidura, el GATT no era, como él decía, una organización supranacional capaz de adoptar reglas que pudieran prevalecer sobre las leyes nacionales. Ahora bien, en ese sentido la historia ha caminado con rapidez, pues en 1995 se creó en
Marrakech la OMc, aunque sin las características que Prebisch había concebido para una organización de ese género. De todas formas, la omc es una organización con rasgos supranacionales y que se acerca a la universalidad, aunque aún no es universal. Recientemente ha ingresado China, pero países como Irán no han sido admitidos y razones políticas impiden que se inicien negociaciones al respecto. Tampoco son miembros Arabia Saudita y la Federación de Rusia, y muchos países de la ex Yugoslavia y Vietnam se encuentran aún en la etapa de negociación. A pesar de lo anterior, la omc tiene actualmente 149 miembros, lo que es bastante razonable en términos de universalidad. Desde esta perspectiva, se puede decir que la visión del informe de Prebisch se ha transformado en realidad.

En cuanto al segundo punto, la exportación de manufacturas, no es necesario repetir lo que todos saben. Para Prebisch, la solución de los problemas de países en desarrollo como los latinoamericanos es la industrialización unida a la posibilidad de exportar cada vez más manufacturas a los centros. Su lucha insistente tuvo como objetivo abrir los mercados de los centros para que pudiesen acceder a ellos las manufacturas de la periferia. Prebisch criticaba la renuencia de esos países a abrir el mercado de las industrias maduras. Este es un caso interesante en que la profecía de Prebisch se ha cumplido en gran medida, pero los resultados no han sido todo lo que él esperaba.

Hoy día, tomadas en conjunto, más del $70 \%$ de las exportaciones de los países en desarrollo son manufacturas, aunque con diversos grados de contenido tecnológico. La participación de los países en desarrollo en el comercio global de manufacturas es muy elevada y crece cada día más. 
Este fenómeno trajo consigo dos problemas principales: primero, una gran concentración de dichas exportaciones y, segundo, el hecho de que la exportación creciente de manufacturas no siempre se ha traducido en el beneficio que Prebisch esperaba del progreso tecnológico o del aumento de la productividad o el valor agregado.

El primer problema se ve claramente en el caso de China. Nadie ignora que en la actualidad China tiende a atraer a todas las industrias maduras del mundo. Los estadounidenses, por ejemplo, ya han transferido a China sectores enteros de su industria manufacturera que hoy ni siquiera tienen protección en los Estados Unidos. Los estadounidenses ya no fabrican los productos de esas industrias, pero las compañías estadounidenses sí los fabrican en China, con mano de obra china. Así sucede con numerosos productos en que China tiene ventajas, sobre todo en el costo de la mano de obra, lo que hace que toda esa industria migre a China.

El caso de Brasil es conocido. En el decenio de 1970, Brasil era el gran exportador de calzado a los Estados Unidos. Hoy día, Brasil provee sólo el $6 \%$ de las importaciones de calzado de los Estados Unidos, mientras que China provee más de $60 \%$. En cierta medida, el traslado de las industrias maduras ha ido en desmedro también de otros países en desarrollo. No se trata solamente de las maquiladoras mexicanas, caso muy conocido en que México ha perdido 250.000 empleos en los últimos años. Otros países como Vietnam van por el mismo camino. En otras palabras, se puede decir que el fenómeno de aumento de la exportación de manufacturas se ha concentrado básicamente en Asia oriental. Hoy existe, incluso entre los asiáticos, una tendencia a trasladar esas industrias a China y Vietnam. Taiwán, provincia de China, por ejemplo, está reteniendo la investigación y el diseño de los productos electrónicos, y fabrica cada vez más sus productos en tierra firme y no en la isla. Este fenómeno no llegó a beneficiar a América Latina.

El segundo problema es que no basta con exportar manufacturas con alto contenido tecnológico, porque lo que cuenta realmente es el valor agregado en dichas exportaciones. ¿Cuál es el aumento de lo que se podría llamar el índice de valor agregado en la manufactura de los productos de exportación? Lo que ha pasado es que muchos países que exportan productos tecnológicamente sofisticados, lo hacen básicamente sobre líneas de ensamblaje en que importan los insumos, los montan y los reexportan. Esto es lo que ocurre con las maquiladoras, y no es el único caso en que el valor agregado es ínfimo.
La contribución a la economía local de ese tipo de actividad existe y es positiva en términos de empleo, salarios y otros aspectos. Pero no es el sueño de Prebisch del gran progreso tecnológico que se propagaría a toda la economía. En cierto modo, esas actividades suelen ser enclaves dentro de una economía y tener pocos vínculos con el resto de ella.

¿Qué pasó en ese terreno con relación a lo previsto en el decenio de 1960? No se había visto entonces con claridad un fenómeno al cual hoy sí estamos acostumbrados: que la producción dejó de ser nacional. A través de las empresas transnacionales, la producción pasó a ser dividida en etapas, que esas empresas asignan a sus diferentes filiales para la producción de determinados bienes o servicios con el fin de obtener economías de escala gracias a la especialización. Es curioso que se haya ignorado el fenómeno por tan largo tiempo, porque en América Latina asistimos al principio de esa tendencia mucho antes de que se hablara de globalización. En mis años de juventud viví en Buenos Aires como encargado del sector comercial de Brasil. En esa época, Brasil aún exportaba a Argentina productos decimonónicos —madera de pino, yerba mate, bananas y café-, lo que comenzaba a cambiar gracias a una idea de la CEPAL y de Prebisch: la Asociación Latinoamericana de Libre Comercio (ALALC), surgida del tratado de Montevideo de 1960. El tratado abrió la posibilidad de negociar lo que se llamaban acuerdos sectoriales de integración. Lo que sucedió es que nosotros los latinoamericanos no teníamos empresas continentales. Nuestras empresas eran nacionales, locales, provinciales. Quienes sacaron provecho del tratado fueron compañías como la IBM, Olivetti, Borroughs, que hicieron uso de esos acuerdos, dividiendo sus líneas de producción, fabricando algunas cosas en México, otras en Argentina o en Brasil. Ese fue el comienzo de lo que más tarde sería uno de los dos grandes motores de la globalización. Uno fue la revolución en telecomunicaciones, en la tecnología de la información; la otra, la internacionalización de las cadenas de producción y distribución.

Lo que Prebisch tenía en mente cuando deseaba que se transfiriesen hacia América Latina las industrias maduras era un sistema nacional de producción integrada. No se había anticipado que eso ocurriría de la manera en que sucedió. Habría que añadir que hay algo que siempre nos ha faltado y aún nos falta, la sensibilidad para potenciar los servicios. Hoy estamos viendo un fenómeno extraordinario en India, que ya está exportando más de 15.000 millones de dólares en servicios, mediante subcontrataciones externas, software y la operación de centros de llamadas. 
Algunos países del Caribe también están haciendo lo mismo. Pero en América Latina aún no estamos realmente preparados para aprovechar el gran potencial de los servicios.

Los países en desarrollo hablan mucho de manufacturas y poco de servicios, sector en el que todos ellos son muy vulnerables. India, por ejemplo, está muy preocupada, ya que en este campo no hay compromisos jurídicos claros, tendientes a proteger las subcontrataciones. El día de mañana, si un país como Estados Unidos o Francia decide tomar medidas contra las subcontrataciones externas, esas medidas no serán consideradas ilegales porque, entre otras cosas - y esta es una situación irónica-, pocos países en desarrollo han adherido al acuerdo de la Ronda de Tokio sobre compras del sector público, que es donde los políticos proteccionistas quieren ahora imponer límites.

Hoy, tanto la CEPAL como la UNCTAD están trabajando más en ese sentido, encarando problemas a los que no habíamos dado quizás la atención debida: los que existen del lado de la oferta del sistema productivo. La CEPAL, con el importante trabajo realizado por Fernando Fajnzylber, lanzó el lema de la transformación productiva con equidad. Pero aún no se ha avanzado mucho en ese campo, ni en materia de transformación productiva ni en términos de equidad.

Es innegable que actualmente, en materia de exportaciones, estamos tendiendo a volver atrás. Hay honrosas excepciones, pero estamos retornando a la especialización en productos que dependen de recursos naturales. El caso de Brasil es típico. El gran éxito brasileño en materia de exportaciones, aparte por ejemplo los aviones de EMBRAER, es la agroindustria (básicamente la agricultura y la ganadería).

Otro tema de carácter más estructural es el de los bloques comerciales. Este no ha sido un tema de Prebisch, muy al contrario. Él quería la integración de América Latina, de los países en desarrollo. Se ha hablado mucho hasta fecha reciente de que el mundo camina hacia una división en tres grandes bloques comerciales: Europa con el euro como moneda; nosotros en el hemisferio occidental con los Estados Unidos y el dólar; y los asiáticos con Japón y el yen. Eso en realidad, ha ocurrido sólo en parte. El gran bloque que realmente ha surgido es el de los asiáticos con los Estados Unidos. Actualmente, la realidad del comercio mundial, del sistema mundial de pagos, es que los asiáticos crecen gracias al mercado estadounidense y compran los dólares y los bonos del Tesoro para que los estadounidenses puedan seguir siendo, no los prestadores de última instancia, sino los consumidores de última instancia.

Llegamos a una situación de simbiosis muy curiosa. Ya hubo quien dijo que hoy existen solamente dos categorías de países en desarrollo. En la primera están los que financian su desarrollo gracias a las exportaciones a los Estados Unidos y la acumulación de reservas que impiden la depreciación de sus monedas frente al dólar y que, al mismo tiempo, se protegen de la volatilidad de los recursos financieros mundiales. Esos países se encuentran en Asia, y entre ellos destaca en particular China, además, por supuesto, de Japón, uno de los miembros principales del grupo. En la otra categoría de países en desarrollo se hallan los que no logran financiarse con sus exportaciones y tienen que hacerlo con endeudamiento, entre los cuales están los latinoamericanos.

Este sistema tiene características preocupantes, pues se basa en la capacidad casi ilimitada de los Estados Unidos de succionar todas las importaciones del mundo. Yo comparo siempre a ese país con los agujeros negros de la astronomía. Estados Unidos está recibiendo el $10 \%$ de los ahorros mundiales. Nunca se había visto algo comparable. Es el gran consumidor y el gran país financiado por los demás. Tiene un déficit comercial de más de 5\% del PIB, y sigue creciendo, a pesar de la relativa depreciación del dólar frente a las monedas europeas. Son los europeos los que están pagando. Esta es la realidad, y no los bloques de que se hablaba anteriormente. La realidad es que los estadounidenses nunca han aceptado límites regionales para su actuación. Entre los acuerdos de libre comercio que han firmado hay tratados con Jordania, con Marruecos, con los africanos en el marco de su ley especial, la Ley relativa al crecimiento y las oportunidades de África (African Opportunity Act). Los estadounidenses no aceptan que África sea el patio trasero de los europeos, y se las está disputando palmo a palmo.

Prebisch imaginaba una reciprocidad que fuera real, no puramente legal. Eso significa una reciprocidad que tome en cuenta las diferencias en nivel de desarrollo y de estructura económica de los países. De ahí viene su idea de un Sistema Generalizado de Preferencias Comerciales, que nació en la primera UNCTAD pero que no ha sido adoptado como él pensaba.

Prebisch quería que el sistema fuera multilateral y no unilateral, en que cada país discute y decide cómo quiere las preferencias. Todas estas ideas están hoy bajo fuertes presiones en dos sentidos diferentes. Existe una tendencia cada vez mayor a la multiplicación de 
acuerdos bilaterales o regionales de libre comercio; estos acuerdos casi siempre desestiman del todo, o en gran medida, las diferencias de nivel de desarrollo e imponen un tipo más legal, más jurídico, de reciprocidad. Este fenómeno se suma a otro: el hecho de que el pensamiento de Prebisch, o el de la UNCTAD de 1964, que veía a los países en desarrollo como un universo compacto poco diferenciado, no corresponde a las nuevas realidades.

Una de esas nuevas realidades es la irrupción de China, fenómeno que nadie podría haber imaginado en 1964, en vísperas de la Revolución Cultural. ¿Es China un país en desarrollo?, ¿o es más bien un país desarrollado, con esa capacidad suya de competir ateniéndose a reglas económicas muy particulares? El fenómeno de Asia y el Pacífico, en general, tiene como extremo opuesto a los llamados países en desarrollo menos adelantados, los 50 países que son los más pobres de los pobres, los miserables de la tierra. Hay que ser tan pobre para entrar en esa categoría de las Naciones Unidas, que de los 35 países del hemisferio occidental, el cual como todos sabemos incluye a América Latina, sólo Haití está en esa lista de los 50. De éstos, 34 son africanos y el Timor oriental ha sido el último en incorporse a esa categoría. Está claro que esos países son heterogéneos, que son distintos de los latinoamericanos, tanto en su historia como en su estructura económica. Muchos de ellos tienen una economía agraria prácticamente de subsistencia. Están en una etapa muy diferente a la que atraviesan los países latinoamericanos. Lo que voy a decir molesta mucho a algunos países en desarrollo, pero esa diferenciación encontrará tarde o temprano una expresión en las normas del comercio.

Es muy difícil imaginar que países como China, India, Brasil, Argentina y otros puedan tener el mismo tratamiento que Burundi, Benin, Chad, Ruanda, Tanzania, Bután. La diferenciación es uno de los grandes retos que tenemos por delante. Se podría decir más de este problema, pero aquí me limitaré a señalar que éste es uno de los temas que no estaban claros ni presentes en la agenda de Prebisch.

No quisiera cerrar el tema de los cambios en el sistema de comercio sin al menos mencionar dos asuntos fundamentales. El primero es que estamos observando un cambio en las bases mismas del sistema multilateral de comercio. Este sistema se desarrolló a partir del siglo XIX sobre la base del principio de no discriminación y la cláusula de la nación más favorecida, que son los dos primeros artículos del Acuerdo General de Aranceles Aduaneros y Comercio. Sin em- bargo, la proliferación de acuerdos de libre comercio, utilizando de manera muy peligrosa los términos del artículo 24 de dicho Acuerdo General, ha permitido una erosión continua de ese principio. Para justificar tal erosión, se dice que los tratados de libre comercio son los elementos con los cuales se construye un sistema de comercio totalmente libre de trabas. Pero en realidad no es así, pues muchas veces tales tratados crean trabas que no existían antes. Sólo para darles un ejemplo: el Tratado de Libre Comercio de América del Norte ha creado reglas de origen en el área de los textiles o de las piezas de automóviles que no existían antes y que constituyen trabas nuevas al libre flujo de mercancías.

Observo esa tendencia con mucha preocupación porque, habiendo sido presidente de las Partes Contratantes del GATT, creo que tengo el deber de defender el sistema multilateral de comercio. También me preocupa que del total del comercio de los Estados Unidos, más de un $40 \%$ esté regido por normas preferenciales.

Quien habla de normas preferenciales habla de normas discriminatorias, por una razón muy sencilla: preferir significa escoger a uno y no a otro. Las diferencias son, pues, discriminatorias. Tengo muchas veces la impresión de que lo que hoy está pasando en el sistema de comercio se parece un poco a lo que ocurrió entre 1971 y 1973, cuando una serie de decisiones ad hoc, fortuitas, tomadas unilateralmente por el presidente Nixon, liquidaron prácticamente la base del sistema de Bretton Woods, al menos en sus dos piedras angulares: el sistema de tipos de cambio con una cierta estabilidad y la plena y libre convertibilidad entre el dólar y el oro. Las instituciones surgidas de Bretton Woods han sobrevivido, el Fondo Monetario Internacional (FMI) está ahí, y pasamos a tener un sistema de tipos de cambio fluctuantes que no corresponde a lo que fue acordado en el Convenio Constitutivo del FMI en 1944. Es otra cosa, otro sistema, y temo que algo parecido está ocurriendo con el sistema multilateral. No es que este vaya a morir, pero se está transformando radicalmente.

El segundo asunto es la idea de la interdependencia, tan importante para Prebisch, quien insistía continuamente en que al Norte, en su interés propio bien entendido, le convenía promover la industrialización del Sur. Prebisch persistió siempre en esa idea: que el progreso, la industrialización del Sur, iba a crear una demanda cada vez más importante de productos sofisticados del Norte, de tecnología del Norte, y sería una fuente adicional de demanda. Lo anterior lo estamos comprobando hoy con China de una manera espectacular. Nadie podrá negar jamás que ese es el papel que China está desempeñando primero con relación a 
Japón. Como se sabe, una de las causas principales de la reciente mejora en la posición japonesa son las exportaciones a China, que crecen en forma extraordinaria. Lo mismo ocurre con relación a los Estados Unidos y muchos países asiáticos. También se han beneficiado Argentina y Brasil, que últimamente han tenido a China como destino del $10 \%$ y del $7 \%$ de sus exportaciones, respectivamente. Ese papel que el crecimiento del Sur puede desempeñar en materia de dinamización del comercio mundial no va en desmedro del Norte, ya que contribuye a aumentar la demanda de países como los Estados Unidos.

Es curioso, por ejemplo, observar lo que ocurre con la República de Corea y que se aplica también a
Malasia y a otros países asiáticos. Para ellos, en los últimos dos o tres años China se ha convertido en su primer mercado, sobrepasando a los Estados Unidos. Cabría pensar que podrían prescindir de este último país, pero no es así, porque, a fin de cuentas, se encuentra siempre a los Estados Unidos. ¿Qué es lo que importa China desde la República de Corea? Importa partes de productos electrónicos de distinta naturaleza que los chinos después ponen en su línea de ensamblaje, montan y reexportan a los Estados Unidos. En el fin de la línea está el agujero negro estadounidense. Otra vez tenemos ahí el bloque gigante, por lo que el comercio Sur-Sur no es una alternativa, sino algo que va junto con el comercio Norte-Sur.

\section{IV}

\section{A modo de conclusión}

Para terminar, cito unas palabras de Prebisch que a mí me gustan mucho, porque son la parte final de su informe a la primera UNCTAD, hace 40 años. Tienen mucho que ver, no con los últimos temas tratados aquí, sino con los problemas subyacentes. Como se habrá notado, en la mayoría de los casos yo no he entregado soluciones; lo que he hecho es plantear los problemas que tenemos por delante.

Prebisch (1964) decía al respecto: "Realismo es también previsión, y un sentido elemental de previsión debiera llevarnos a interpretar el signo de los acontecimientos que están ocurriendo en el mundo en desarrollo". Por ello, añadía, las páginas de su informe eran "un acto de fe en la posibilidad de persuadir, de penetrar con estas ideas en donde tiene que penetrarse y en la posibilidad de provocar reacciones constructivas".

Y concluía así su exhortación:

"Los hechos están allí, no pueden negarse. Y si las maneras de encararlos que aquí se sugiere no son aceptables, habrá que buscar otras que lo sean. Porque el problema es inescapable. Nunca lo había tenido el mundo en esta forma ni en estas dimensiones. Y tampoco había tenido el mundo las enormes posibilidades que ahora tiene para resolverlos, ni la convicción — que se extiende cada vez más - de que también es factible actuar en forma consciente y deliberada sobre las fuerzas de la técnica y la economía en la prosecución de grandes designios".

\section{Bibliografía}

Bhagwati, J. (1984): Comentario, en G. Meier y D. Seers (comp.) CEPAL, 1996, Pioneros del desarrollo, Madrid, Tecnos.

CEPAL (Comisión Económica para América Latina y el Caribe) (2003): Balance preliminar de las economías de América Latina y el Caribe. 2003, LC/G.2223-P, Santiago de Chile. Publicación de las Naciones Unidas, $\mathrm{N}^{\circ}$ de venta: S.03.II.G.186.

Prebisch, R. (1949): El desarrollo económico de la América Latina y algunos de sus principales problemas, E/CN.12/89, Santiago de Chile, Comisión Económica para América Latina y el Caribe (CEPAL).

(1964): La significación de la Conferencia de las Naciones Unidas sobre Comercio y Desarrollo, Actas de la Conferencia de las Naciones Unidas sobre Comercio y Desarrollo
(Ginebra, 23 de marzo-16 de junio de 1964), E/CONF.46/141, Nueva York, Naciones Unidas. Publicación de las Naciones Unidas, $\mathrm{N}^{\mathrm{o}}$ de venta: 64.II.B.12.

(1983): La crisis del capitalismo y la periferia, Problemas económicos del Tercer Mundo, Buenos Aires, Editorial de Belgrano, septiembre.

(1984): Cinco etapas en mi pensamiento sobre el desarro1lo, en G. Meier y D. Seers, Pioneros del desarrollo, Madrid, Tecnos.

Ricupero, R. (2001): La globalización de Raúl Prebisch, documento presentado en el Seminario "La teoría del desarrollo en los albores del siglo XXI: Evento conmemorativo del centenario del nacimiento de don Raúl Prebisch" (Santiago de Chile, 28 y 29 de agosto de 2001). 